\title{
ARTIGO
}

do 10.22481/praxisedu.v15i33.5298

\section{UNIVERSIDADE PÚBLICA: MAPEAMENTO DAS POLÍTICAS DE ENSINO, PESQUISA, EXTENSÃO E INOVAÇÃO}

\author{
PUBLIC UNIVERSITY: MAPPING OF POLICIES OF EDUCATION, RESEARCH, \\ EXTENSION AND INNOVATION
}

\author{
UNIVERSIDAD PÚBLICA: MAPA DE LAS POLÍTICAS DE ENSEÑANZA, \\ INVESTIGACIÓN, EXTENSIÓN E INNOVACIÓN
}

\author{
Raimunda Maria da Cunha Ribeiro \\ Universidade Estadual do Piauí - Brasil
}

\begin{abstract}
Resumo: No sentido de compreender o lugar da universidade no progresso das nações, nos orientamos pela seguinte questão de pesquisa: qual o discurso institucional predominante da universidade pública quando se refere as suas políticas de ensino, pesquisa, extensão e inovação, tendo como ponto de referência o Plano de Desenvolvimento Institucional? O estudo tem como objetivos: compreender o conceito de universidade no percurso de sua história enquanto instituição; identificar os desafios da universidade frente às dimensões do desenvolvimento promovido a partir do conhecimento produzido no contexto desta instituição; analisar as declarações dos Planos de Desenvolvimento Institucional de Universidades Federais no que diz respeito à política universitária de ensino, pesquisa, extensão e inovação; identificar, a partir do que está nos Planos de Desenvolvimento Institucional, as propostas de desenvolvimento, levando em consideração as dimensões cultural, social, ambiental e econômica. A metodologia foi qualitativa, considerando a análise documental como técnica de coleta de dados e a análise de conteúdo para dar tratamento aos dados. Foram analisados Planos de Desenvolvimento Institucional de 27 Universidades Federais. A categoria fundante da análise foi: desafios da universidade frente às dimensões do desenvolvimento a partir das políticas de ensino, pesquisa, extensão e inovação. Os dados nos indicam que a universidade se apresenta fortemente comprometida com a produção e socialização do conhecimento científico e tecnológico como primazia, de modo que os próprios documentos inserem na política de inovação, de forma muito contundente, a relação com novos mercados.
\end{abstract}

Palavras-chave: Universidade pública. Política universitária. Desenvolvimento.

\begin{abstract}
In order to understand the place of the university in the progress of nations, we are guided by the following research question: what is the predominant institutional discourse of the public university when it refers to its policies of teaching, research, extension and innovation, having as reference point the Institutional Development Plan? The study aims to: understand the concept of university in the course of its history as an institution; identify the challenges of the university facing the dimensions of development promoted from the knowledge produced in the context of this
\end{abstract}


institution; analyze the statements of the Institutional Development Plans of Federal Universities with regard to the university policy of teaching, research, extension and innovation; identify, from the institutional development plans, development proposals, taking into account the cultural, social, environmental and economic dimension. The methodology was qualitative, considering documentary analysis as data collection technique and content analysis to give data treatment. Institutional Development Plans of 27 Federal Universities were analyzed. The founding category of the analysis was: university challenges to the dimensions of development from the policies of teaching, research, extension and innovation. The data indicate that the university is strongly committed to the production and socialization of scientific and technological knowledge as primacy, so that the documents themselves insert in the policy of innovation, very forcefully, the relationship with new markets.

Keywords: Public university. University policy. Development.

Resumen: En el sentido de comprender el lugar de la universidad en el progreso de las naciones, nos orientamos por la siguiente cuestión de investigación: cuál es el discurso institucional predominante de la universidad pública cuando se refiere a sus políticas de enseñanza, investigación, extensión e innovación, teniendo como punto de referencia el " Plan de Desarrollo Institucional? El estudio tiene como objetivos: comprender el concepto de universidad en el recorrido de su historia como institución; identificar los desafíos de la universidad frente a las dimensiones del desarrollo promovido a partir del conocimiento producido en el contexto de esta institución; analizar las declaraciones de los Planes de Desarrollo Institucional de Universidades Federales en lo que se refiere a la política universitaria de enseñanza, investigación, extensión e innovación; identificar, a partir de lo que está en los Planes de Desarrollo Institucional, las propuestas de desarrollo, teniendo en cuenta las dimensiones cultural, social, ambiental y económica. La metodología fue cualitativa, considerando el análisis documental como técnica de recolección de datos y el análisis de contenido para dar tratamiento a los datos. Se analizaron Planes de Desarrollo Institucional de 27 Universidades Federales. La categoría fundante del análisis fue: desafíos de la universidad frente a las dimensiones del desarrollo a partir de las políticas de enseñanza, investigación, extensión e innovación. Los datos nos indican que la universidad se presenta fuertemente comprometida con la producción y socialización del conocimiento científico y tecnológico como primacía, de modo que los propios documentos inserta en la política de innovación, de forma muy contundente, la relación con nuevos mercados.

Palabras clave: Universidad pública. Política universitaria. Desarrollo.

\section{Introdução}

Em decorrência do cenário de mudanças em que o mundo atravessa, países veem na universidade, a possibilidade de estarem incluídos no circuito mundial de conhecimento e competências. A preocupação com a produção do conhecimento, dar-se pelo fato de ser este, conforme argumenta Severino (2002), elemento específico fundamental na construção do destino da humanidade, e neste contexto, a educação superior se configura como processo mediante o qual o conhecimento se produz, se reproduz, se conserva, se sistematiza, se organiza, se transmite e se universaliza. 
O fato da educação superior aparecer como central na formação de profissionais exige das universidades uma reorganização de suas funções básicas, assim como a declaração de sua missão, de forma a atender as demandas mais urgentes de seu tempo. Contudo, a importância desse nível de ensino é, em alguma medida, traduzida pela contratualização, por uma prestação de contas mais apertada e por uma pressão mais forte do lado da eficácia e da eficiência. Significa dizer, pois, que a necessidade de melhor qualificação dos recursos humanos é um requisito da economia e uma aspiração da população que acredita que as pessoas mais educadas (no sentido de quem mais estudou) conseguem melhores empregos e melhores rendas. O relevo legitimo dado à formação de pessoas com competência para circular no mercado de empregos da sociedade e da economia do conhecimento não pode querer dizer, contudo, a redução da educação superior a projetos de formação unicamente para a empregabilidade (LESSARD, 2006; SCHWARTZMAN; CASTRO, 2013; MAGALHÃES, 2011).

Tendo em vista que as universidades "são responsáveis pela qualificação e capacitação de um grande número de profissionais [...] são, em consequência, afetadas pelo processo de globalização e precisam responder às novas exigências que lhes são colocadas" (DUARTE, LIMA JÚNIOR, BATISTA, 2007, p. 160), que dentre as quais podemos citar: a internacionalização de suas atividades básicas, a orientação para o mercado, pesquisa e inovação, qualificação e número de publicações do corpo docente.

No sentido de compreender o lugar da universidade no progresso das nações, nos orientamos para desenvolvimento deste estudo, pela seguinte questão de pesquisa: qual o discurso institucional predominante da universidade pública quando se refere as suas políticas de ensino, pesquisa, extensão e inovação, tendo como ponto de referência o Plano de Desenvolvimento Institucional? Para respondê-la nos pautamos pelos seguintes objetivos: compreender o conceito de universidade no percurso de sua história enquanto instituição; identificar os desafios da universidade frente às dimensões do desenvolvimento promovido a partir do conhecimento produzido no contexto desta instituição; analisar as declarações dos Planos de Desenvolvimento Institucional de Universidades Federais no que diz respeito à política universitária de ensino, pesquisa, extensão e inovação; identificar, a partir do que está nos Planos de Desenvolvimento Institucional, as propostas de desenvolvimento, levando em consideração as dimensões cultural, social, ambiental e econômica.

A metodologia segue a abordagem qualitativa, por assim, descrever e qualificar um dado fenômeno, pois é um tipo de abordagem dentro da investigação científica que se foca no 
caráter subjetivo do objeto analisado, aqui especificamente, as propostas das universidades nos seus Planos de Desenvolvimento Institucional sobre o conceito de desenvolvimento e suas dimensões.

Alguns aspectos da pesquisa qualitativa foram levados em considerações nesta investigação, tais como: o discurso das universidades pesquisadas através da política universitária; a ênfase no que as instituições propõem enquanto desenvolvimento. A técnica utilizada para coleta de dados foi a análise documental, considerando sua importância, seja complementando informações obtidas por outras técnicas, seja desvelando aspectos novos de um tema ou problema (LÜDKE e ANDRÉ, 1986). O documento base para a análise foi o conjunto dos Planos de Desenvolvimento Institucional de 27 Universidades Federais, com sede nas capitais. A categoria fundante da análise foi: desafios da universidade frente às dimensões do desenvolvimento a partir das políticas de ensino, pesquisa, extensão e inovação.

A primeira seção de que trata este artigo apresenta a discussão, sob o ponto de vista teórico, da universidade enquanto instituição e sua evolução histórica, o conceito de desenvolvimento na perspectiva da universidade; a responsabilidade social da universidade contemporânea. A segunda seção apresenta os dados advindos da pesquisa empírica, especificamente da análise dos documentos (PDI), a qual nos leva a discutir sobre os desafios da universidade frente às dimensões do desenvolvimento a partir das políticas de ensino, pesquisa, extensão e inovação. Para esta discussão, elencamos as seguintes categorias: frequência das dimensões de desenvolvimento nas declarações de missão no PDI; frequência das políticas universitárias anunciadas no Planos de Desenvolvimento Institucional; frequência das diretrizes relacionadas à política universitária (ensino, pesquisa, extensão, inovação) anunciadas no Planos de Desenvolvimento Institucional. A técnica adotada para a interpretação dos dados empíricos foi a análise de conteúdos sob a orientação dos estudos de Bardin (2010): pré análise, exploração do material, inferência e interpretação, cujo objetivo reside na compreensão de conteúdos e as condições de produção destes.

\section{Universidade: origem e evolução}

A universidade surgiu na Idade Média, ligada à Igreja Católica e com o apoio dos senhores feudais, compreendia espaço das ideias e de produção do saber, de produção do conhecimento para gerar o pensamento crítico e formar intelectuais e lideranças. Neste contexto, os homens mediáveis viam na universidade e nos livros uma janela para o futuro da 
humanidade. Embora sob a égide da doutrina da Igreja, neste espaço as pessoas buscavam possibilidades de inserção no campo político e cultural da sociedade e, em alta medida, formalizou-se os primeiros avanços na produção do conhecimento e no desenvolvimento do pensamento crítico e científico e, por esta razão, o surgimento da universidade está entre os principais acontecimentos da época. Segundo Lampert (1996), as universidades medievais eram corporações surgidas espontaneamente, mas, supervisionadas pela Igreja, gozavam de privilégios e força para mudar aspectos políticos, econômicos, sociais e culturais da época.

Foi no esplendor da filosofia escolástica, no século XIII, que nasceram as grandes universidades, como a de Bolonha, de Paris e de Oxford, instituições do gênio cristão medieval, foram o protótipo das universidades europeias, que a seguir se formaram (CORREIA, 1949), constituindo-se o modelo de universidade tradicional, que se implantou por todo território europeu sob a proteção da Igreja romana (TRINDADE, 1999). As primeiras universidades surgiram de criações espontâneas das necessidades do meio, como uma resposta dos homens medievais à novas exigências históricas.

O estudo das universidades medievais permite a compreensão quanto ao nível do pensamento crítico e do desenvolvimento das ciências na Europa (OLIVEIRA, 2007), isso porque o surgimento destas instituições representou importante fato histórico na evolução do pensamento ocidental, fundamental para o avanço intelectual naquele continente (CORREIA, 1949). O autor considera, então, que as três primeiras universidades foram responsáveis para construir ambiente propício ao desenvolvimento de novas ideias, que tomaram como ponto de partida o pensamento extraído da antiguidade clássica. Consideramos, porém, para esta discussão os achados de Oliveira (2007), em relação ao fato específico que teria marcado o nascimento da universidade. Seus estudos apontam que a origem dessa instituição pode ser explicada pela existência de um grande mestre, por um privilégio imperial, por uma concessão eclesiástica, mas que nada assegura, com exatidão, o acontecimento que permitiu o nascimento dessa instituição. Um dado importante em seus estudos refere-se à primeira Lei (Authentica Habita), de forma que ressalta nela a importância dos homens de saberes, além do que, historiadores a veem como um dos fatos ligados às origens das universidades medievais.

A universidade constituiu a grande realização da Idade Média na esfera intelectual, dada a notável influência no campo da cultura, da ciência e do desenvolvimento intelectual; foi a mais importante criação da Idade Média e, neste sentido, compreender a sua história, implica compreender nossa identidade, assim como, uma possibilidade para entendermos a construção do conhecimento, das ciências humanas e naturais, reconhece Lampert (1996). 
Oliveira (2007) ressalta que as universidades eram corpos dentro do universo medievo e que principiavam a ser constituídas por intermédio de leis novas, portanto, buscavam nos privilégios, proteções e elementos essenciais para a sua existência. O que se pode resgatar do modelo medieval de universidade é uma concepção de instituição baseada em três elementos básicos: formação teológico-jurídica; organização corporativa; autonomia em face ao poder político e da Igreja institucionalizada local (TRINDADE, 1999).

O fim da Idade Média e o início da Idade Moderna significou a transição do sistema feudal para a primeira fase do capitalismo e, em decorrência, todas as mudanças intelectuais, sociais, políticas, culturais e religiosas dos novos paradigmas da humanidade, dando origem ao Estado Moderno com diferente organização política e econômica. A Idade Moderna representou uma realidade histórica, marcada pelo desenvolvimento das cidades, o fortalecimento da economia mercantil e a formação de monarquias nacionais; representou, também, um mundo novo, o qual passou a exigir outros comportamentos e outros conhecimentos para lidar com duas dimensões fundamentais da modernidade: a industrialização e o modo de produção capitalista. Na origem da universidade está a transição da humanidade de uma etapa para outra: da vida rural para a vida urbana, do pensamento dogmático para o racionalismo, do mundo espiritual para o mundo terreno, da Idade Média para a Renascença, representando novos tempos e novos paradigmas (BUARQUE, 1994). Nesta discussão, assimilamos os argumentos de Silveira; Bianchetti (2016), de que desde as origens do Estado Moderno, a concepção de universidade é atravessada pela dimensão instrumental, de forma a responder às demandas dos campos econômico, industrial, tecnológico e urbano da ordem capitalista. Neste sentido, o projeto de universidade moderna se estruturou para ser inovador e diferente de tudo o que constituiu esta instituição até aquele momento (PEREIRA, 2009).

A universidade que temos hoje, traz em sua missão muito do que foi a universidade nessa época, assentada na razão científica, uma vez que a ciência é um dos projetos mais importantes da modernidade. Neste contexto de transformações, a universidade moderna impôs sua presença com a fundação da Universidade de Berlim, em 1809 por Humboldt, tal como os princípios da era moderna, incorporou como diretriz o desenvolvimento da racionalidade e da ciência. Na obra "Sobre a organização interna e externa das instituições científicas superiores em Berlim" (1810), escrita por Wilhelm von Humboldt, o autor faz uma sistematização teórica sobre a universidade, sua organização e gestão e trata, também, sobre a liberdade de produção da ciência pura e infinita, além da relação estreita, porém autônoma, 
entre Estado e universidade (SILVEIRA; BIANCHETTI, 2016). Os traços dominantes de sua argumentação eram o nacionalismo e a identificação com a política prussiana de unificação da Alemanha, bem como a valorização da ciência e da investigação empírico-indutiva como instrumentos de auto superação (RIBEIRO, 1982).

Assim, a grande inovação da universidade de Berlim está na produção científica, visando o desenvolvimento, a partir de uma relação ativa entre aluno e professor na busca pelo conhecimento, pondo a ciência no centro das relações universitárias. Encontramos na universidade de Berlim, conforme assinalam Silveira; Bianchetti (2016); Pereira (2009), o germe da universidade voltada para o desenvolvimento, de forma a cumprir papel preponderante no processo de mediar a construção e a modernização do Estado.

Destacamos, entretanto, outro modelo de universidade voltado para formação profissional e de formação política, atrelado aos interesses do Estado, disposto a seguir as orientações do poder instituído. É dentro desse ideário que se colocou o modelo de universidade napoleônica, ao mesmo tempo, de coerção, controle social e construção de hegemonia em torno da ideologia do Estado (SILVEIRA; BIANCHETTI, 2016). A universidade napoleônica rompeu com a tradição das universidades medievais e organizou-se, pela primeira vez, subordinada ao Estado nacional (TRINDADE, 1999); foi antes um produto dos impactos renovadores da revolução industrial do que um desdobramento vegetativo da universidade medieval de Paris; nasceu fora da velha universidade corporativa, fechada, aristocrática, eclesiástica; depois de iluminar o mundo, teve de institucionalizar-se sob o signo do positivismo (RIBEIRO, 1982). Nesta discussão cabem os argumentos de Pereira (2009), quando afirma que suas normas eram emanadas do exterior, sua autonomia era relativa e seu controle pelas forças de poder era preponderante. O modelo napoleônico de universidade refletia em uma concepção educacional fundamentada nas necessidades práticas da classe dominante, subjugada ao poder e assumida com a função de conservação da ordem social, com vistas à construção de uma identidade nacional.

A universidade moderna teve suas atividades iniciadas no século XIX, desdobrandose até nossos dias (TRINDADE, 1999), introduzindo uma nova forma de relação entre Estado e universidade. Se o papel da universidade pouco mudou, a situação social do mundo pósmoderno aliada à dinâmica do conhecimento científico estão a exigir desta instituição uma revolução quanto à sua missão e sua responsabilidade social, bem como a compreensão da finalidade do conhecimento no desenvolvimento social, ambiental, econômico e cultural. Nenhuma instituição foi tão importante na formação científica e profissional como tem sido a 
universidade, representando, portanto, patrimônio cultural, intelectual e científico da humanidade. A universidade do nosso tempo é abalada por varáveis, dentre as quais podemos enumerar: globalização da economia, a qual redesenha o território e o papel do Estado; políticas neoliberais, que transmitem o direito de cidadania para a liberdade de mercado; produção científico-tecnológica cada vez mais concentradora e excludente, conforme assinala Pereira (2009). Implica, pois reconhecermos, que numa sociedade capitalista, a universidade faz parte da superestrutura ideológica e hegemônica da neoliberalização e que, portanto, sua função neste espectro, tem sido predominantemente a transmissão dos valores da classe dominante.

A missão social da universidade tende a correr sério risco de ser suplantada por um modelo de educação baseado na economia do conhecimento, amplamente reforçado com o advento da sociedade pós-industrial, em que a produtividade do conhecimento surge como um fator determinante na posição competitiva de uma indústria, de uma empresa e de um país (DRUCKER, 2007). A universidade, por seu turno, tem assumido a posição de uma instituição visivelmente focada na produção do conhecimento e na racionalidade científica. Nesta direção estão os argumentos de Afonso (2015), de que esta instituição, por um lado, muito tem contribuído para alcançar legitimidade e divulgar o conhecimento e a investigação produzidos, fazendo com este mesmo conhecimento científico contribua igualmente para legitimar a própria missão da universidade; por outro lado, o autor argumenta que a legitimidade da universidade em produzir conhecimento, também, para fins sociais e culturais está posta em causa e, de certa forma, sendo substituída pela legitimidade mercantil, uma vez que o valor do conhecimento é medido mais por critérios quantificáveis, seguindo a lógica da competitividade empresarial. Não podemos negar que esta lógica empresarial é transportada para a universidade, inclusive a do setor público, emergindo neste sentido, a competição institucional tanto entre os pares quanto entre as instituições. Como exemplo citamos a publicação em periódicos qualificados, que tem se tornado o principal critério do sucesso acadêmico no ambiente competitivo do ensino superior (ALTBACH, 2015).

A universidade é, dentre as instituições sociais, a que mais acompanhou a complexidade da sociedade, talvez por isso, é um campo formado por diferentes interesses e marcado por lutas, competições, ideologias e jogos de poder, ademais, é solicitada a responder uma multiplicidade de expectativas. Segundo Pereira (2009), ao lado das funções básicas de ensino, pesquisa e extensão, que em si já demandam atividades complexas, outras solicitações são impostas a ela: contribuir na esfera pública; liderar o processo de desenvolvimento e, 
diríamos, em múltiplas dimensões; estimular uma melhora para a qualidade do seu entorno; colocar-se à disposição do setor produtivo; gerar fundos de financiamento de suas atividades; fazer parcerias com empresas para o desenvolvimento; favorecer soluções científicas e tecnológicas para os problemas da sociedade global. Assim, entender a universidade do nosso tempo, é entender qual é a sua verdadeira essência, quais as suas contribuições no plano de desenvolvimento local e nacional e qual a sua responsabilidade social.

Parece haver consenso, tendo como ponto de partida a lógica da sociedade neoliberal, que a universidade se assuma revestida de princípios do campo empresarial, inovadora e parceira do setor produtivo, espaço de produção de ciência, tecnologia e inovação, de forma a combinar suas atividades de ensino, pesquisa, extensão e inovação para a promoção do desenvolvimento econômico. A utilização da universidade como instrumento político a serviço do poder, a luta pela autonomia e pela gestão democrática são elementos da universidade medieval que se encontram, também, na universidade do nosso tempo (LAMPERT, 1996). Falar em universidade é falar de elitização, formação intelectual, ciência e tecnologia para o desenvolvimento cultural, social, econômico e ambiental, mas é também, falar de responsabilidade social e do conhecimento por ela produzido e seus impactos em todas as áreas da vida e da sociedade.

As universidades em todo o mundo estão sendo convocadas a desempenhar sua responsabilidade social, também como uma bandeira de luta no enfrentamento do imperialismo do capital, do mundo empresarial e do mercado de trabalho. Altbach (2015) argumenta que na época contemporânea, a responsabilidade da universidade é educar pessoas para que trabalhem efetivamente em um mundo cada vez mais tecnológico, fornecendo habilidades técnicas e uma educação que inspire a habilidade de pensar criticamente. Em uma sociedade complexa, interconectada e globalizada, as universidades tendem a executar seu trabalho na direção da cooperação com outros setores da sociedade e com parceiros para além das fronteiras regionais e nacionais, incluindo essencialmente o setor produtivo e o campo econômico. Implica dizer que a universidade se vê diante do dilema de cumprir bem suas funções básicas de ensino, pesquisa, extensão e inovação para o desenvolvimento social e, ao mesmo tempo, adaptar-se, de forma satisfatória, às amplas mudanças impostas pela globalização e pelo neoliberalismo dominante e excludente.

Após esta contextualização acerca das origens e evoluções da universidade, passamos à próxima seção, na qual tratamos sobre os desafios desta instituição frente às dimensões do desenvolvimento, levando em consideração a política de ensino, pesquisa, 
extensão e inovação, como discurso institucional declarado nos Planos de Desenvolvimento Institucional.

\section{A política de ensino, pesquisa, extensão e inovação}

Esta seção foi elaborada a partir dos dados advindos da análise documental, tendo como documento de referência 27 Planos de Desenvolvimento Institucional de universidades públicas federais brasileiras. Do processo de coleta de dados, trazemos para a discussão as seguintes categorias: dimensões de desenvolvimento nas declarações da missão; frequência das políticas universitárias de ensino, pesquisa, extensão e inovação identificadas nos documentos; diretrizes das políticas universitárias relacionadas ao ensino, pesquisa, extensão e inovação.

O Plano de Desenvolvimento Institucional é um documento de planejamento que reúne as propostas da instituição para um período de cinco ou até dez anos. Nos documentos analisados no âmbito deste estudo, foi possível extrair do texto "Apresentação" algumas categorias, as quais consideramos importante citá-las: a) o processo de construção do PDI; b) o PDI como instrumento de orientação para o desenvolvimento da sociedade; c) o PDI como visão empreendedora da universidade pública.

As principais considerações declaradas nos documentos acerca do processo de elaboração traduzem um percurso participativo e dialógico, conforme excertos do próprio texto: traduz uma construção coletiva; traz uma atuação inteligente e democrática do ponto de vista do planejamento participativo, estratégico e avaliativo, ampliando a capacidade de gestão administrativa da universidade; plano sujeito a ajustes, conforme a realidade sócioeducacional; construído com ampla participação dos seus setores sociais, envolvendo a sociedade e todas as unidades acadêmicas e administrativas.

Em termos de orientação para o desenvolvimento da sociedade, identificamos elementos próprios da extensão universitária impressos no corpus dos documentos: o PDI pauta sua ação em um conjunto de valores, base de seu forte compromisso com a sociedade; projeta a universidade para o futuro em um formato democrático e sustentável; documento que identifica a instituição no que concerne à sua filosofia de trabalho e quais são os caminhos que a instituição elegeu para se consolidar em um bem público indispensável ao exercício da cidadania; parte do reconhecimento de que produzir conhecimento, formar recursos humanos são atribuições das instituições universitárias, para enfim, contribuir na 
resolução dos grandes problemas sociais; tem como objetivo a excelência acadêmica e ações resultantes no fortalecimento do ensino, da pesquisa e da extensão, como forma de consolidação da universidade em direção ao desenvolvimento da sociedade; como princípios filosóficos, define a formação profissionais e a produção de conhecimento com compromisso para o desenvolvimento social e ambiental.

No processo de análise, foi possível identificar o PDI como um documento do ponto de vista da universidade empreendedora, a partir das seguintes definições: documento prospectivo e de referência sobre as metas, objetivos e ações a serem desenvolvidas; instrumento gerencial que agrega ideias para realizar esforços e mobilizar recursos de maneira coerente; define os rumos da instituição em torno de seu desenvolvimento e suas metas; documento de planejamento a ser considerado dentro da gestão estratégica; instrumento legal de planejamento e gestão.

Reconhecemos que a universidade pública, através de suas declarações em documentos, como é o caso do Plano de Desenvolvimento Institucional, vê-se diante de duas situações, as quais imprimem a sua complexidade: por um lado manter-se comprometida em realizar sua responsabilidade social em todas as suas atividades, de forma a contribuir com o desenvolvimento social, cultural, econômico e sustentável; por outro lado, a universidade tem sido influenciada por forças externas, que a têm impulsionado a adotar uma postura empreendedora, de parceira com o setor produtivo, visando sua própria sustentabilidade financeira.

A universidade brasileira incorporou influências tanto do modelo napoleônico, voltado para a formação profissional e atrelada aos interesses do Estado quanto, também, do modelo implementado por Humboldt, cujo papel está na mediação da construção e modernização do Estado através, principalmente, das atividades de pesquisa. Consideramos, entretanto, influências do modelo norte-americano, especificamente após a II Guerra Mundial, na formação profissional para fins de atendimento ao mercado, da universidade empreendedora, encoberta pelo véu do imperialismo neoliberal, de forma a identificarmos que, da política universitária posta em documentos institucionais, emerge o conceito de inovação atrelado à dimensão do desenvolvimento econômico. Como diria Ribeiro (1982), somos herdeiros de um legado e de um fardo: um legado positivo de antecedentes que mostram como, em certas circunstâncias, algumas universidades fizeram-se promotoras de renovação e do progresso; e um legado negativo - o nosso fardo - implícito nos 
procedimentos pelos quais outras universidades foram levadas a atuar, principalmente, como agentes de consolidação do statu quo.

Para compreender a história da universidade brasileira não o fazemos sem relacioná-la com o conjunto da sociedade, na ótica de sua dimensão política. Naturalmente, uma de suas funções capitais é fazer o maior número possível de cidadãos herdarem o patrimônio artístico, literário e intelectual da humanidade; é também função dominar a ciência de seu tempo no mais alto nível possível de conhecimento e de investigação, porque a ciência é o discurso do homem sobre sua experiência na terra, é a explicação mais completa e responsável de suas observações sobre a natureza e sobre as relações entre os homens e as coisas, e seus nexos causais. O desafio maior e mais pungente se traduz agora em transformá-la (RIBEIRO, 1982; FÁVERO, 2006).

A universidade é convocada a ser palco de discussões sobre a sociedade, ser espaço em que se desenvolve um pensamento teórico-crítico, posicionamentos, como também encaminhamentos de propostas e alternativas de solução dos problemas (FÁVERO, 2006). Sem embargos, a missão da universidade brasileira traduz o conceito de desenvolvimento, incluindo em sua declaração categorias como: desenvolvimento social, desenvolvimento sustentável, desenvolvimento cultural, desenvolvimento econômico. Ser protagonista no plano de desenvolvimento de uma nação é papel capital da universidade de nosso tempo, que se constitui um aprendizado difícil, segundo Fávero (2006), por vezes exaustivo, mas necessário. Desta feita, apresentamos na Tabela 1 o discurso institucional quanto às dimensões de desenvolvimento nas declarações da missão da universidade.

Tabela 1. Frequência das dimensões de desenvolvimento nas declarações da missão - PDI

\begin{tabular}{|c|c|c|}
\hline \multirow{8}{*}{ 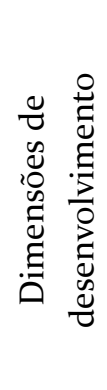 } & Desenvolvimento & Frequência \% \\
\hline & Da sociedade & $26 \%$ \\
\hline & Local, regional e nacional & $26 \%$ \\
\hline & Sustentável & $26 \%$ \\
\hline & Social, econômico, ambiental, tecnológico e cultural & $18 \%$ \\
\hline & Intelectual, humano e sociocultural & $5,4 \%$ \\
\hline & Humano para a democracia e a cidadania & $5,4 \%$ \\
\hline & Desenvolvimento econômico & $5,4 \%$ \\
\hline
\end{tabular}

Fonte: PDI das IES federais pesquisadas

Encontramo-nos em um momento de profundas e rápidas mudanças no cenário mundial que, em alta medida, afetam a cultura, o comportamento social, a economia, a política e a educação. Todavia, esta situação de mudança, segundo Zabalza (2007), não é 
novidade para a universidade - via de regra afetada por tais mudanças - ainda que externamente transmita a imagem de algo sólido e pouco variável, pois, durante seus vários séculos de história, esteve modificando sua orientação e sua projeção social. Reconhecemos, entretanto, que estamos incorporando, em ritmo de marcha forçada mudanças na estrutura, nos conceitos e nas dinâmicas de funcionamento, cujo objetivo remete a colocá-la em condições de enfrentar os novos desafios que as forças sociais lhes obrigam assumir.

Um dos desafios da universidade em nosso tempo é manter o equilíbrio entre produzir conhecimento para fins de desenvolvimento econômico e produzir conhecimento para o desenvolvimento social, cultural e sustentável. Esta discussão traz como pano de fundo a crescente desvalorização da democratização em prol da retórica da qualidade e da excelência - germes do empreendedorismo (MORGADO, 2009). A Tabela 1 nos dá indicativos de que a universidade mantém o discurso da promoção do conhecimento para o desenvolvimento nas dimensões social (26\%) e sustentável (26\%), destacadas nos documentos. Em frequência de 18\%, identificamos nas declarações da missão, as dimensões agrupadas: social, econômica, ambiental, tecnológica e cultural. E também, o desenvolvimento econômico em $5,4 \%$ dos documentos.

Outros desafios indicados por Ribeiro (1982) para a universidade de nosso tempo: a opção entre a espontaneidade e o planejamento como política de desenvolvimento da universidade; a opção entre o compromisso da universidade com a nação e seus problemas de desenvolvimento e a postura acadêmica tradicional, desinteressada do destino nacional ou incapaz de relacionar a atividade universitária com uma atividade cidadã. Não se trata, porém, de expandir o existente, mas, conforme argumenta Teixeira (1989), de se implantar a cultura científica nas raízes da universidade, a fim de criar o quadro de competências necessário para se conduzir a transformação da sociedade brasileira.

De posse das informações dos documentos analisados, consideramos oportuno apresentar, a partir de dados de pesquisas recentes, o debate sobre a relação entre universidade e desenvolvimento, foco de nossa investigação. Pesquisamos no portal da Capes com o descritor "universidade e desenvolvimento" e extraímos para análise 14 artigos. Os dados das publicações analisadas nos apontam, em alta frequência (93\%), para o modelo da universidade empreendedora em prol o desenvolvimento econômico, uma discussão na direção contrária aos dados apresentados na Tabela 1. Escapando desta estatística, apenas um dos artigos mostra a importância da universidade, princípios e valores em prol do 
desenvolvimento da comunidade e da formação para a autonomia, cidadania e para a melhora da qualidade de vida.

O discurso que percebemos a partir destes dados, aponta que a universidade está se modernizando e adotando estratégias próprias do campo das organizações. A relação entre universidade-empresa tem se intensificado e, dentro deste contexto, as universidades podem contribuir de forma eficiente com a geração de novas tecnologias e conhecimentos, manifestando-se como uma alternativa de inovação juntamente com a iniciativa privada (GOMES; GONÇALO; PEREIRA; VARGAS, 2014). O empresariado anseia que as universidades estejam presentes no contexto no qual estão inseridas, e que a interação é dependente da visão e da necessidade de cada empresa (CHAIS; MACHADO; SCOPEL; BOHRER, 2015). A contribuição da universidade pública para a inovação e o desenvolvimento regional depende de líderes acadêmicos capazes de mobilizar a universidade na realização de atividades de interação com a sociedade, estimulando as bases de uma universidade empreendedora (FERREIRA; LEOPOLDI, 2013). Tendo em conta a natureza, amplitude e implicações da cientifização das sociedades modernas, aprofundamos o argumento da cultura científica. Defendemos uma visão humanista de ciência, que deve guiar o desenvolvimento da cultura científica na sociedade, que se querem abertas e democráticas (CACHAPUZ, 2016).

Em síntese, identificamos que quase a totalidade das produções analisadas, trata da perspectiva da interação universidade-empresa, com capacidade, eficiência, competitividade, empreendimento, geração de renda, produtividade, termos antes exclusivos das organizações da iniciativa privada. Não há de estranharmos que a universidade pública já caminha na direção de uma política universitária voltada para garantir seu lugar no campo do empreendedorismo.

Ensino, pesquisa, extensão e inovação são as dinâmicas que conduzem a universidade a cumprir sua missão e imprimir a marca de sua existência, assim, desde a Idade Média até os dias atuais. A frequência com que tais dinâmicas estão declaradas no PDI estão demonstradas na Tabela 2.

Tabela 2. Frequência das Políticas Universitárias anunciadas no Planos de Desenvolvimento Institucional

\begin{tabular}{l||l||l||l}
\hline \multicolumn{4}{c}{ Políticas Universitárias } \\
\hline Ensino & Pesquisa & Extensão & Inovação \\
\hline \hline $25(92,5 \%)$ & $24(88,9 \%)$ & $24(88,9 \%)$ & o9 $(33,3 \%)$ \\
\hline Fonte: PDI das IES federais pesquisadas
\end{tabular}


A Tabela 2 nos indica que as funções básicas de ensino, pesquisa, extensão e inovação estão presentes na quase totalidade dos Planos de Desenvolvimento Institucional. A política de inovação, diferentemente dos artigos analisados na base da Capes, não é uma referência significativa nos documentos institucionais, aparecendo em apenas 33,3\%, o que nos leva, forçosamente, a considerar a existência de uma lacuna entre o proclamado nos PDI's e o que a universidade está realizando, de forma a materializar sua política universitária e cumprir sua posição de vanguarda no plano de desenvolvimento de forma expressiva no setor econômico.

Após a identificação das políticas universitárias nos documentos institucionais, passamos a identificar a frequência das diretrizes de tais políticas, conforme demonstrado na Tabela 3.

Tabela 3. Frequência das diretrizes da Política Universitária relacionadas ao ensino, pesquisa, extensão, inovação anunciadas no Planos de Desenvolvimento Institucional

\begin{tabular}{|c|c|c|c|}
\hline \multirow{13}{*}{ 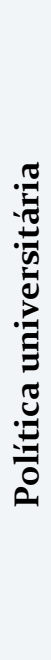 } & \multicolumn{2}{|r|}{ Diretrizes } & Frequência \\
\hline & \multirow[t]{3}{*}{ Ensino } & Formação profissional & $93 \%$ \\
\hline & & Compromisso social (RS) & $44 \%$ \\
\hline & & Produção de conhecimento & $37 \%$ \\
\hline & \multirow[t]{3}{*}{ Pesquisa } & Produção e ampliação do conhecimento & $100 \%$ \\
\hline & & Desenvolvimento social/regional & $42 \%$ \\
\hline & & Padrão de excelência universal/internacionalização & $29 \%$ \\
\hline & \multirow[t]{3}{*}{ Extensão } & Formação acadêmica e profissional & $75 \%$ \\
\hline & & Diálogo com a sociedade & $71 \%$ \\
\hline & & Promoção do conhecimento & $42 \%$ \\
\hline & \multirow[t]{3}{*}{ Inovação } & Produção científica e transferência tecnológica & $67 \%$ \\
\hline & & Parceria com o setor produtivo/empreendedorismo & $33 \%$ \\
\hline & & Novos mercados/Parques Tecnológicos & $22 \%$ \\
\hline
\end{tabular}

Fonte: PDI das IES federais pesquisadas

Para a política de ensino, destacamos nos documentos três dimensões: formação profissional (93\%); compromisso social (44\%); produção do conhecimento (37\%).

Sobre a formação profissional (93\%) identificamos: formação do profissional cidadão com autonomia profissional e capacidade de intervir e contribuir com sua área profissional e com a sociedade como um todo; formação não apenas técnico-científica, mas a formação cultural e ética para o desenvolvimento sustentável; formação de cidadãos qualificados para construção de uma sociedade inclusiva e sustentável; formação adequada ao perfil de egresso, passando pela inovação e qualificação, internacionalização, e gestão 
acadêmica; formação que possibilita ao indivíduo o desenvolvimento de sua capacidade de gerar conhecimentos a partir de uma postura dialógica com a realidade; formação geral e profissional, visando o desempenho competente, crítico e ético de atividades profissionais, quanto para o prosseguimento de estudos em nível de pós-graduação.

O compromisso social (44\%), presente nos documentos, nos direcionam para o seguinte: considerar que a universidade é parte integrante e atuante do contexto que a determina como um bem público, portanto, deve priorizar a melhoria da qualidade de vida dos diversos grupos sociais; fomentar o ensino que ultrapasse o espaço da sala de aula, estabelecendo a relação-educação-sociedade; manter a indissociabilidade entre o ensino, a pesquisa e a extensão; promover a transformação social sustentável; ampliar as relações com a sociedade para melhor contribuir como o desenvolvimento sustentável; assegurar a inclusão, a melhoria continuada das práticas acadêmicas e a maior mobilidade nacional e internacional do estudante; buscar a excelência da aprendizagem; manter o compromisso de ações estratégicas que permitam a construção de uma proposta de excelência acadêmica com inclusão social.

Quanto à produção de conhecimento (37\%), os documentos destacam o seguinte: o ensino deve ser voltado para a produção e a socialização de conhecimentos, que serão utilizados como recurso de educação destinado à formação; a universidade deve estimular o aluno uma atitude crítica e investigativa que contribua para a compreensão da realidade na qual está inserida; promover a produção e difusão de conhecimento que resultem na melhoria da qualidade de vida das populações por ela atingida; promover uma educação voltada para a democratização do conhecimento, superando a linearidade da construção deste, possibilitando a ampliação e ressignificação da docência e discência no que se refere pensar e atuar na realidade em prol de uma perspectiva plural marcada pela complexidade e interpretação de saber de forma a contribuir para o rompimento da rigidez dos currículos e para a adequação de conteúdos e habilidades voltados a acompanhar o dinamismo da sociedade; todas as modalidades devem ser voltadas para a busca, a produção e a socialização de conhecimentos e técnicas, e são utilizadas como recurso de educação destinado à formação ética, crítica, técnica, científica, cultural e artística.

A política de pesquisa, tal como definida nos documentos apontam para três dimensões: produção e ampliação do conhecimento (100\%); promoção do desenvolvimento social (42\%); busca pelo padrão de excelência universal (29\%). 
A produção e ampliação do conhecimento (100\%) pode ser descrita nestes termos: garantir a geração e ampliação do conhecimento, estando vinculada à criação e à produção cultural, científica, tecnológica e inovadora; esforçar para a consolidação de Grupos de Pesquisa; articular atividades de pesquisa com o ensino e a extensão; estreitar o diálogo com universidades, centros de pesquisa, órgãos de fomento e consulares com outros países, com vistas à intensificação do intercâmbio acadêmico e à promoção da interculturalidade; incentivar a geração de pesquisas de impacto social e de alto nível; implementar uma política institucional de captação de recursos externos para infraestrutura de grande porte destinada à política e à inovação; buscar ativamente a inserção da pesquisa qualificada e identificada com os interesses socioeconômicos, sem perder de vista sua atuação no desenvolvimento de projetos produtores de conhecimento universal; incentivar o amento qualitativo da produção científica.

A dimensão da pesquisa referente à promoção do desenvolvimento social (42\%) traduz o seguinte: contribuir para uma formação cidadã e para o fortalecimento de políticas públicas que atendam às necessidades da população; consolidar pesquisas, visando o desenvolvimento científico, cultural, econômico, social e ambiental, em conformidade com princípios éticos, na busca de excelência acadêmica e articulação com o ensino e a extensão; produzir, divulgar e transferir saberes e tecnologias voltadas para o desenvolvimento sustentável, para a preservação dos ambientes naturais e para o reaproveitamento de recursos não renováveis; estruturar a pesquisa científica, tecnológica e inovação para o desenvolvimento social e a redução de desigualdades sociais.

A pesquisa em termos de consolidação de padrão de excelência (29\%) traduz o seguinte: zelar pela qualidade na elaboração do conhecimento científico e priorizar o enfoque regional e o padrão de excelência universal pela internacionalização; incentivar a comunidade acadêmica a realizar e ampliar sua inserção em projetos científicos nacionais e internacionais; buscar cooperações institucionais nacionais e internacionais, em redes de alta complexidade, sobretudo, em editais de agências já consolidadas; reconhecer e divulgar os núcleos de excelência; estimular o intercâmbio e a cooperação nacional e internacional como forma de melhoria da qualidade da produção científica; promover o protagonismo nacional e internacional em ciência e tecnologia.

A política de extensão, tal como posta nos documentos, passa pelas seguintes dimensões: formação acadêmica e profissional (75\%); diálogo com a sociedade (71\%); promoção do conhecimento (42\%). 
A dimensão formação acadêmica e profissional (75\%) pode ser interpretada nestes termos: contribuir com a formação do ser humano em sua plenitude, possuidor de condições bioantropológicas, mentais e socioculturais, trabalhadas a partir da realidade social; proporcionar instrumentos de formação acadêmica, articuladas às atividades de pesquisa e ensino; primar pela inserção da dimensão acadêmica da extensão na formação dos discentes e na construção do conhecimento; realizar experiências de articulação externa no campo do ensino e da pesquisa, contribuindo para o processo de formação integral do aluno; proporcionar um processo de formação profissional, como fator intrínseco aos projetos pedagógicos dos cursos; favorecer intervenções transformadoras da realidade social e promover processos de investigação e de formação profissional com princípios para a construção de uma sociedade democrática e solidária; fortalecer a função social da universidade, formando profissionais que promovam diálogo crítico, fecundo e propositivo com as questões postas pela realidade histórica e social; promover aportes decisivos à formação de profissionais capazes de atuação academicamente inovadora e socialmente comprometida como os valores de desenvolvimento social e humano.

Quanto ao diálogo com a sociedade (71\%), a extensão tem como finalidade: promover o diálogo com a sociedade, em um contexto de complexidade próprio do século XXI; acolher os problemas e apelos da sociedade, quer através de grupos sociais quer através de questões que surgem de suas atividades; firmar o compromisso da universidade com a sociedade, mediado por um nexo bidirecional; viabilizar a relação transformadora entre universidade e sociedade; articular, desenvolver, coordenar e apoiar as atividades de extensão, junto à sociedade e à comunidade universitária; promover ações que intensificam o diálogo com a sociedade e o intercâmbio de saberes entre a comunidade acadêmica e os diversos segmentos sociais; expressar-se em quatro eixos: impacto e transformação, interação dialógica, interdisciplinaridade, indissociabilidade (ensino, pesquisa e extensão); estimular a participação nas questões sociais, sobretudo as que envolvem saúde, educação, cultura, tecnologia, direitos humanos, trabalho, meio ambiente e comunicação; comprometer-se com a construção de uma sociedade livre de desigualdades, de misérias e de exclusões.

Quando os documentos se referem à produção do conhecimento $(42 \%)$ através da extensão, vão nesta direção: divulgar e/ou promover o conhecimento, atendendo às necessidades de iniciação, de atualização ou aperfeiçoamento científico, técnico, artístico, cultural e qualificação profissional; produzir conhecimento, contribuindo para viabilizar a relação transformadora entre a universidade e a comunidade; promover o conhecimento, 
através da cultura, da democratização do acesso ao saber e da intervenção solidária junto à comunidade para a transformação social; a partir do diálogo entre os saberes acadêmicos e populares, a universidade assume o propósito de produzir e tornar acessível o conhecimento, gerar o pensamento crítico, reflexivo e autônomo; incentivar a construção do conhecimento, socializando através de debates, publicações, apresentações e exposições.

Quando os documentos se referem à política de inovação, podemos identificar estas dimensões: produção científica e transferência tecnológica (67\%); parceria com o setor produtivo/empreendedorismo (33\%); novos mercados/Parques Tecnológicos (22\%).

A dimensão referente à produção científica e transferência tecnológica (67\%) traduz o seguinte: estimular e valorizar a atividade criativa na produção científica, tecnológica e artística de seu corpo docente, discente e técnico-administrativo; contribuir para a criação de um ambiente favorável à geração de novo conhecimento e sua transferência para a sociedade, em consonância com a missão da universidade de criar e disseminar o conhecimento na ciência, tecnologia, cultura e artes; propor ações estratégicas para incentivar o aumento da propriedade intelectual e a transferência de tecnologia; promover, como estratégia, a transferência de tecnologia em prol do desenvolvimento econômico, científico, tecnológico e social do país.

Quanto à dimensão referente à parceria com o setor produtivo/empreendedorismo (33\%), os documentos apontam: potencializar a criação intelectual de atividades financeiras realizadas em conjunto com outras instituições, entidades ou empresas, nacionais ou estrangeiras e empreendimentos econômicos solidários; promover a proteção da propriedade intelectual de modo a garantir que sua utilização gere benefícios em termos de desenvolvimento da relação universidade-empresa, de ampliação do conhecimento, produtos e processos gerados nos centros tecnológicos, de divulgação e crédito das atividades científicas e tecnológicas da universidade e de justa recompensa à universidade e aos criadores; primar pela estruturação de uma central de empresa juniores, com apoio à criação e manutenção de incubadoras; fomentar a cultura do empreendedorismo através de palestras de sensibilização e cursos.

Por fim, a dimensão que diz respeito aos novos mercados/Parques Tecnológicos $(22 \%)$ tem como finalidade viabilizar o acesso ao desenvolvimento de novos mercados de gestão tecnológica e inovação por meio de parques tecnológicos.

Em linhas gerais, e em conformidade como que extraímos dos Planos de Desenvolvimento Institucional, podemos considerar que a responsabilidade da universidade 
provém de sua função social e educacional traduzida em produzir, socializar, aplicar e difundir o conhecimento para o desenvolvimento. É compromisso da universidade promover ensino, pesquisa, extensão e inovação de forma a oferecer à juventude oportunidades de amadurecimento intelectual - como herdeira do patrimônio cultural humano - e formação ideológica com vistas a fazer dos estudantes cidadãos responsáveis perante seu povo e seu tempo (RIBEIRO, 1982). O desafio é cuidar para que a política universitária não se configure meramente em um paradigma utilitarista baseado na lógica do mercado e nos princípios neoliberais, e para que a responsabilidade social universitária e a promoção do desenvolvimento social e cultural não cedam o lugar para princípios meramente econômicos.

\section{Considerações finais}

Este estudo teve como finalidade mapear a política de ensino, pesquisa, extensão e inovação e, para tanto, nos propomos entender o papel da universidade e sua relação com o desenvolvimento e as possíveis formas de materializar sua responsabilidade social, inserida em contextos históricos específicos até chegarmos na universidade brasileira consolidada. $\mathrm{O}$ estudo empírico através da análise dos Planos de Desenvolvimento Institucional nos possibilitou: entender sobre a política universitária e sua relação com a realidade social, política e econômica que a circunda; identificar a preocupação da universidade, através do próprio discurso institucional, em se colocar como instrumento de orientação para o desenvolvimento da sociedade, e também, como uma instituição assumidamente com visão empreendedora.

A universidade se apresenta fortemente comprometida com a produção e socialização do conhecimento científico e tecnológico como primazia, de modo que os próprios documentos inserem na política de inovação, de forma muito contundente, a relação com novos mercados. Precisamos entender, como atores sociais da universidade pública, que o valor atribuído ao conhecimento não precisa ser preponderantemente o valor econômico e que a universidade que queremos não precisa ser uma empresa com valores únicos do mercado e princípios únicos do neoliberalismo.

A universidade de que precisamos, aos olhos de Ribeiro (1982), antes de existir como um fato no mundo das coisas, deve existir como um projeto, uma utopia, no mundo das ideias. Nossa tarefa, pois, consiste em definir as linhas básicas deste projeto utópico, cuja formulação deverá ser suficientemente clara e atraente para poder atuar como uma força 
mobilizadora na luta pela reforma da estrutura vigente. Deverá ter, além disto, a objetividade necessária para ser um plano orientador dos passos concretos pelos quais passaremos da universidade atual à universidade necessária.

Longe de esgotar todas as inquietações sobre as funções básicas da universidade, elegemos este estudo como fundamental para entendermos o seu lugar na complexidade de uma sociedade mercadológica. Enfim, questionamentos ainda são necessários: o ensino proferido na universidade pública tem se preocupado com que tipo de formação profissional? O conhecimento por ela produzido tem alimentado a fome de quem? A extensão tem se comprometido em realizar a responsabilidade social universitária ou tem sido meramente impulsionadora das parcerias com o setor produtivo? A inovação, presente em pouco mais de $30 \%$ dos PDI, o que quer dizer com o acesso ao desenvolvimento de novos mercados?

Embora não temos respostas totalizadoras para estas questões, emergidas do corpus dos documentos, nos permitimos dizer que a universidade, apesar de pressionada pelas forças externas para transformar o conhecimento em moeda de alto valor econômico, traz consigo, mediante a sua responsabilidade social, as mais variadas possibilidades de transformação social, de uma sociedade desigual para uma sociedade mais democrática e mais justa.

\section{REFERÊNCIAS}

AFONSO, Almerindo Janela. A educação superior na economia do conhecimento, a subalternização das ciências sociais e humanas e a formação de professores. Avaliação, Campinas; Sorocaba, SP, v. 20, n. 2, p. 269-291, jul. 2015.

ALTBACH, G. Philip. O que conta para a produtividade nas universidades de pesquisa? Ensino Superior. UNICAMP. International Higher Eucation 79, 2015. Disponível em https://www.revistaensinosuperior.gr.unicamp.br Acesso em 27 de março de 2018.

BARDIN, Laurence. Análise de Conteúdo. Lisboa-Portugal: Edições 70, LDA, 2010.

BUARQUE, Cristóvam. A aventura da universidade. São Paulo: Editora da Unesp, 1994.

CACHAPUZ, Antônio Francisco. Universidade, cultura e cientifização das sociedades modernas. Revista Internacional de Educação Superior, v. 2(2), p229-240, 2016.

CHAIS, Cassiane; MACHADO, Claralucia Prates; SCOPEL, Alexandra Mazzochi; BOHRER, Cristina. Universidade empreendedora: a ótica dos empresários sobre o posicionamento empreendedor da universidade na contribuição para o desenvolvimento regional. Revista Gestão Universitária na América Latina, v. 8(4), p. 57-73, 2015. 
CORRÊIA. Alexandre. A universidade medieval. Revista da Faculdade de Filosofia, Ciências e Letras de São Bento, São Paulo, v. 45, n. 2, p. 292-329, dez. 1949. Acrescentar Disponível em http://www.revistas.usp.br/rfdusp/article/view/66131 Acesso em 10 de agosto de 2018.

DRUCKER, Peter. Sociedade pós-capitalista. Lisboa: Actual, 2007.

DUARTE, Roberto Gonzalez; LIMA JÚNIOR, Antônio Ferreira de; BATISTA, Raquel Viana Lessa. O processo de internacionalização das instituições de ensino superior: o caso das Pontifícias Universidades Católicas de Minas Gerais e do Paraná. E\&G Economia e Gestão, Belo Horizonte, v. 7, n. 14, p. 1-178, 1, 2007.

FÁVERO, Maria de Lourdes de Albuquerque. A universidade no Brasil: das origens à Reforma Universitária de 1968. Educar, Curitiba, n. 28, p. 17-36, 2006.

FERREIRA, André; LEOPOLDI, Antonieta. A contribuição da universidade pública para a inovação e o desenvolvimento regional: a percepção de gestores e pesquisadora. Revista Gestão Universitária na América Latina, v. 6(1), p. 60-82, 2013.

GOMES, Myller Santos; GONÇALO, Claudio Reis; PEREIRA, Christiane Drozdek; VARGAS, Sandra Lohn. A inovação como conexão para o desenvolvimento de parcerias entre universidade-empresa. Navus: Revista de Gestão e Tecnologia, v. 4(2), p. 78-91, 2014.

LAMPERT, Ernani. A universidade: da idade Média à época atual. BIBLOS, Rio Grande, v. 8, p. 199-210, 1996.

LESSARD, Claude. A universidade e a formação profissional de docentes: novos questionamentos. Educação e Sociedade. Campinas, vol. 27, n. 94, p. 201-227, jan./abr. 2006. Disponível em www.cedes.unicamp.br. Acesso em 31 de março de 2018.

LÜDKE, Menga; ANDRÉ, Marli. Pesquisa em educação: abordagens qualitativas. São Paulo: EPU, 1986.

MAGALHÃES, António. Cenários, dilemas e caminhos da educação superior europeia. Perspectiva, Florianópolis, v. 29, n. 2, p. 623-647, jul./ dez. 2011.

MORGADO, José Carlos. Processo de Bolonha e ensino superior num mundo globalizado. Educ. Soc, Campinas, v. 30, n. 106, p.37-62, jan/abr. 2009. Disponível em $<$ http://www.cedes.unicampi.br> Acesso em: 08 de agosto de 2018.

OLIVEIRA, Terezinha. Origem e memória das universidades medievais a preservação de uma instituição educacional. Varia História, Belo Horizonte, vol. 23, n 37: p.113-129, Jan/Jun 2007.

PEREIRA, Elisabete Monteiro de Aguiar. A universidade da modernidade nos tempos atuais. Avaliação, Campinas; Sorocaba, SP, v. 14, n. 1, p. 29-52, mar. 2009.

RIBEIRO, Darcy. A universidade necessária. 4ª Ed. São Paulo: Paz e Terra, 1982. 
SEVERINO, Antônio Joaquim. Educação e universidade: conhecimento e construção da cidadania. Interface. Comunicação, Saúde, Educação, v6, n10, p.117-24, fev 2002.

SCHWARTZMAN, Simon; CASTRO, Cláudio de Moura. Ensino, formação profissional e a questão da mão de obra. Ensaio: aval. pol. públ. Educ., Rio de Janeiro, v. 21, n. 80, p. 563624, jul./set. 2013.

SILVEIRA, Zuleide Simas da; BIANCHETTI, Lucídio. Universidade moderna: dos interesses do Estado-nação às conveniências do mercado. Revista Brasileira de Educação, v. 21, n. 64, p. 79-99, Jan-mar, 2016.

TEIXEIRA, Anísio. Ensino superior no Brasil: análise de interpretação de sua evolução até 1969. Rio de Janeiro: FGV, 1989.

TRINDADE, Hélgio. Universidade em perspectiva: sociedade, conhecimento e poder.

Revista Brasileira de Educação, n. 10, p. 5-15, Jan-abr, 1999.

VALLAEYS, François. O que significa responsabilidade social universitária? Estudos, v.24, n.36, jun/2006, p.35-56.

ZABALZA, Miguel A. O ensino universitário: seu cenário e seus protagonistas. Porto Alegre: Artmed, 2007.

\section{$\underline{\text { SOBRE A AUTORA }}$}

\section{Raimunda Maria da Cunha Ribeiro}

Doutora em Educação pela Pontifícia Universidade Católica do Rio Grande do Sul (PUCRS). Realizou Estágio Pós-doutoral na (UNOESC). Professora da Universidade Estadual do Piauí (UNESPI), Teresina-PI, lotada no campus de Corrente-PI, no curso de Pedagogia. Coordenadora o GREPE - Grupo de Estudos e Pesquisas Educacionais. Coordenadora da Rede Mapa no estado do Piauí. E-mail: raicribeiro@ hotmail.com

ORCID https://orcid.org/0000-0001-6196-731X

Recebido em: 27 de outubro de 2018

Aprovado em: 13 de abril de 2019

Publicado em: 01 de julho de 2019 